Barth, J., Schoop, M., Gloskovskii, A., Shkabko, A., weidenkaff, A., \& Felser, C. (2010). Investigation of the thermoelectric properties of the series TiCo1-xNixSnxSb1-x. Zeitschrift für Anorganische und A11gemeine Chemie, 636(1), 132-136. https://doi.org/10.1002/ zaac. 200900349

\title{
Investigation of the thermoelectric properties of the series
}

$\mathrm{TiCo}_{1-\mathrm{x}} \mathrm{Ni}_{\mathbf{x}} \mathrm{Sn}_{\mathrm{x}} \mathrm{Sb}_{1-\mathrm{x}}$

Joachim Barth,${ }^{[\mathrm{a}]}$ Leslie M. Schoop, ${ }^{[\mathrm{a}]}$ Andrei Gloskovskii, ${ }^{[\mathrm{a}]}$ Andrey Shkabko, ${ }^{[\mathrm{b}]}$ Anke Weidenkaff, ${ }^{[b]}$ and Claudia Felser ${ }^{*[a]}$

${ }^{[a]}$ Institut für Anorganische Chemie und Analytische Chemie, Johannes-Gutenberg Universität, Mainz, Germany

${ }^{[b]}$ EMPA, Swiss Federal Laboratories for Materials Testing and Research, Solid State Chemistry and Catalysis, CH-8600 Duebendorf, Switzerland

Dedicated to Professor Simon, on the occasion of his $70^{\text {th }}$ birthday

*Prof. Dr. Claudia Felser

Institut für Anorganische Chemie und Analytische Chemie

Johannes-Gutenberg Universität

Staudinger Weg 9 
D-55099 Mainz, Germany

Fax: +49 $613139-26267$

E-mail: felser@uni-mainz.de

\begin{abstract}
The effect of the simultaneous substitution of Co by $\mathrm{Ni}$ and $\mathrm{Sb}$ by $\mathrm{Sn}$ in the solid solution $\mathrm{TiCo}_{1-\mathrm{x}} \mathrm{Ni}_{\mathrm{x}} \mathrm{Sn}_{\mathrm{x}} \mathrm{Sb}_{1-\mathrm{x}}$ was systematically investigated. The number of valence electrons does not change by this substitution and therefore the resistivity stays semimetallic or semiconducting. The series was synthesized by arcmelting and the thermoelectric properties were determined. It was found out that the substitution of Co and $\mathrm{Sb}$ by $\mathrm{Ni}$ and $\mathrm{Sn}$ reduces the thermal conductivity to $2 \mathrm{Wm}^{-1} \mathrm{~K}^{-1}$ at $400 \mathrm{~K}$. The reduction is caused by Ti rich prolate micro structures that were found by energy dispersive X-ray spectroscopy investigations. The Seebeck coefficient and the resistivity increase with increasing amounts of $\mathrm{Co}$ and $\mathrm{Sb}$. The highest Power factor was found for the composition $\mathrm{TiCo}_{0.8} \mathrm{Ni}_{0.2} \mathrm{Sn}_{0.8} \mathrm{Sb}_{0.2}$ at $900 \mathrm{~K}$ with the value of $9.2 \mu \mathrm{Wcm}^{-}$ ${ }^{1} \mathrm{~K}^{-1}$ Keywords: Intermetallic phases, Materials Science, Low Temperature Studies
\end{abstract}




\section{Introduction}

Recently the search for new materials for thermoelectric applications has attracted a lot of interest. This is caused by the ever-growing demand of energy and the decline of fossil fuels. Thermoelectric materials can be used to convert waste heat to energy. The determining factor for the energy conversion is the figure of merit $\mathrm{Z}$, which is a function of the Seebeck coefficient $S$, the electrical resistivity $\rho$, the thermal conductivity $\kappa$, and the absolute temperature $T$. The aim is to find compounds that exhibit a high absolute value of $S$ combined with low values of $\rho$ and $\kappa$. A very promising material class in this field are Half Heusler compounds of the LiAlSi structure type. Among them are the compounds TiNiSn and TiCoSb [1] that have been in the focus of research in the recent past. Both compounds have 18 valence electrons (VE) and are supposed to be narrow gap semiconductors or semimetals [2-5], one of the preconditions for a good thermoelectric material. In the series of $\mathrm{TiNi}_{1-\mathrm{x}} \mathrm{Co}_{\mathrm{x}} \mathrm{Sn}_{1-\mathrm{x}} \mathrm{Sb}_{\mathrm{x}} \mathrm{Ni}$ was substituted by Co and to an equal amount $\mathrm{Sn}$ by $\mathrm{Sb}$. The number of valence electrons does not change by this substitution and therefore the semiconducting behavior should be retained.

\section{Insert Table 1 here}

A decrease of thermal conductivity is expected due to the substitution of two atomic positions in the crystal lattice and the accompanying increase of phonon scattering. A similar approach has been successfully applied before by the substitution of Co in TiCoSb by equal parts of $\mathrm{Ni}$ and $\mathrm{Fe}$ [6]. It is known that the substitution of $\mathrm{Sb}$ by $\mathrm{Sn}$ in 
TiCoSb [7] and the substitution of Sn by Sb in TiNiSn [8] reduce the thermal conductivity.

\section{Experimental Section}

The solid solution $\mathrm{TiCo}_{1-\mathrm{x}} \mathrm{Ni}_{\mathrm{x}} \mathrm{Sn}_{\mathrm{x}} \mathrm{Sb}_{1-\mathrm{x}}$ with $(\mathrm{x}=0,0.2,0.4,0.5,0.6,0.8,0.9,0.95,1)$ has been prepared by arc melting of stoichiometric amounts of the elements. The arcmelting was performed in an Ar atmosphere of several hundred mbar. Special care was taken to avoid oxygen contamination. This was ensured by melting Ti inside the vacuum chamber before melting the compound. To ensure the homogeneity of the samples they were remelted several times and flipped before each melting step. After each melting the samples were weighed. The mass loss of the samples was less than $1 \%$ and compensated by the addition of elemental Sb. The samples were not annealed due to the loss of $\mathrm{Sb}$ at high temperatures and the decrease of homogeneity during the annealing in TiCoSb based compounds [9]. Bars of about $(2 \times 2 \times 8) \mathrm{mm}^{3}$ were cut from the pellets and polished before measuring. For the inspection of the surface a scanning electron microscope (Jeol JSM-6400) equipped with an EDX-Detection system (EUMEX ${ }^{\circledR}$ EDX) was used. The samples were measured in a vacuum of $3 \times 10^{-6}$ mbar. The primary electron beam had an energy of $20 \mathrm{keV}$ and the EDX detector was mounted at an angle of $35^{\circ}$ to the sample surface normal. For the quantitative data correction the ZAF method was applied. For the image acquisition the Digital Image Processing System (DIPS) and for the quantitative chemical analysis the program WINEDS 4.0 were used. The probing depth of EDX is about 2 microns. For powder investigations a part of the 
samples was crushed by hand using a mortar. The structure has been investigated by X-ray powder diffraction (XRD) using Mo K $\alpha$ radiation (Bruker D8 Advance).

The measurements of the Seebeck coefficient, thermal conductivity, and resistivity were carried out with a Physical Property Measurement System Model 6000 (Quantum Design) equipped with the options P400, P600, and P640. The measurements with the PPMS were carried out for all compounds in the temperature range from $2 \mathrm{~K}$ to $400 \mathrm{~K}$. The bars were contacted by copper stripes that were wrapped around the sample to homogenize the current. Additionally the stripes were glued to the sample with a silver epoxy paste to improve the contact. Before contacting the samples were polished to remove oxide layers. The thermoelectric properties were measured at a pressure of about $1.2 \times 10^{-4}$ mbar. An additional correction term for the heat loss at the heating shoes was introduced and applied to the thermal conductivity data as it was suggested by Quantum Design $[10,11]$. In the temperature range from $340 \mathrm{~K}<\mathrm{T}<900 \mathrm{~K}$ the electrical conductivity and the Seebeck coefficient were determined with the RZ2001i unit of Ozawa Science, Japan. The Seebeck coefficient and the electrical conductivity were recorded simultaneously in an Ar atmosphere. The Seebeck coefficient was measured by a steady state method and the electrical conductivity by a DC four point method. The measurements of the electrical resistivity were carried out for selected compounds with $x=0.2,0.5,0.8,0.9,0.95$. The low and high temperature thermoelectric properties of the unsubstituted TiCoSb and TiNiSn compounds were reported by us and others $[8,12,13,14]$. 


\section{Results and Discussion}

\section{Structural Properties}

The series $\mathrm{TiCo}_{1-\mathrm{x}} \mathrm{Ni}_{\mathrm{x}} \mathrm{Sn}_{\mathrm{x}} \mathrm{Sb}_{1-\mathrm{x}}$ has been prepared by arc melting. X-ray powder diffraction was performed on all compounds. As an example the XRD pattern for $\mathrm{TiCo}_{0.2} \mathrm{Ni}_{0.8} \mathrm{Sn}_{0.8} \mathrm{Sb}_{0.2}$ is shown in Figure 1. The major phase was identified to be of the LiAlSi structure type. The arrows mark the reflexes arising from impurity phases. The impurity phases were identified to be $\mathrm{TiNi}_{2} \mathrm{Sn}, \mathrm{Ti}_{6} \mathrm{Sn}_{5}$, and $\mathrm{Sn}$. This is in agreement with the findings of Katayama for unannealed TiNiSn samples [15]. No impurities were detected for the phases with $0<x \leq 0.6$. The amount of impurity is rising with increasing $\mathrm{Ni}$ and $\mathrm{Sn}$ content for $\mathrm{x}>0.6$. The inset of Figure 1 shows the lattice parameter $\mathrm{a}(\mathrm{x})$ as a function of the $\mathrm{Ni}$ and $\mathrm{Sn}$ concentration $\mathrm{x}$.

\section{Insert Figure 1 here}

The crosses represent the literature values for TiCoSb [16] and TiNiSn [17]. According to Vegard [18] the lattice parameter increases linearly in the solid solution from TiCoSb to TiNiSn. A linear fit was applied to the data points in the concentration range $0<\mathrm{x} \leq$ 0.6. For $x>0.6$ the data deviates from the fit with increasing $x$. This behavior is related to the increasing amount of impurity observed for increasing values of $\mathrm{x}$. Therefore EDX measurements were performed for a sample with a large deviation from the expected lattice constant, for $\mathrm{TiCo}_{0.1} \mathrm{Ni}_{0.9} \mathrm{Sn}_{0.9} \mathrm{Sb}_{0.1}$. In Table 2 the elemental composition of the sample is shown. The emission lines of Sn and Sb could not be 
resolved and therefore they are displayed together. The obtained composition for the whole field of view is in the expected error range of the measurements.

\section{Insert Figure 2 here}

For the determination of the elemental distribution the field of view was set to $105 \mu \mathrm{m}$ $\times 95 \mu \mathrm{m}$. The micrographs were taken in the Ni K $\alpha, \mathrm{Co} \mathrm{K} \alpha, \mathrm{Ti} \mathrm{K} \alpha, \mathrm{Sn} \mathrm{L} \alpha, \mathrm{Sb} \mathrm{L} \alpha$, and in an integral image. The micrographs are displayed in Figure 2. In the micrograph taken in $\mathrm{Ti} \mathrm{K} \alpha$ the distribution of Ti throughout the sample is displayed. The distribution is homogeneous except for some prolate areas where an excess of $\mathrm{Ti}$ is observed. The prolate areas are oriented from the right lower corner to the left upper corner. At the Ti rich areas deficits of $\mathrm{Ni}$ and $\mathrm{Co}$ are observed in the respective micrographs. The distribution of $\mathrm{Sn}$ and $\mathrm{Sb}$ is homogeneous throughout the sample.

\section{Insert Table 2 here}




\section{Electrical resistivity}

The electrical resistivity for $\mathrm{TiCo}_{1-\mathrm{x}} \mathrm{Ni}_{\mathrm{x}} \mathrm{Sn}_{\mathrm{x}} \mathrm{Sb}_{1-\mathrm{x}}$ is displayed in Figure 3. For $0 \leq \mathrm{x} \leq 0.4$ the compounds show semiconducting behavior whereas for $\mathrm{x}>0.4$ the compounds are metallic. The overall resistivity of the compounds is decreasing with increasing $\mathrm{x}$ values. It has been shown by Balke [4] that the semiconducting state of TiCoSb relies strongly on the correct structure. Disorder decreases or even closes the band gap. It is assumed that for higher Ni and Sn concentrations the disorder in the samples is increased. This leads to a decrease of the gap at the Fermi energy for $0<x \leq 0.4$. For $x>0.4$ the gap is closed.

\section{Insert Figure 3 here}

This leads to a reduction of the resistivity and for $\mathrm{x}>0.4$ to a metallic behavior. The comparison of the resistivity data with annealed samples [19] shows that annealing has a big influence on the electric properties of the samples with high $\mathrm{Ni}$ and $\mathrm{Sn}$ concentrations. Without annealing the disorder and the amount of impurity phases is increased and the electrical resistivity is reduced.

\section{Thermal conductivity}

The thermal conductivity was investigated in the temperature range from $2 \mathrm{~K}$ to $400 \mathrm{~K}$ for selected compositions of $\mathrm{TiCo}_{1-\mathrm{x}} \mathrm{Ni}_{\mathrm{x}} \mathrm{Sn}_{\mathrm{x}} \mathrm{Sb}_{1-\mathrm{x}}$, the results are displayed in Figure 4. Unfortunately we could not measure the thermal conductivity up to higher temperatures. The highest values for the thermal conductivity are observed for unsubstituted TiCoSb $[19,20]$. With a decrease of the Co and Sb content the thermal conductivity decreases until reaching a minimum for $\mathrm{x}=0.9$. Then the thermal conductivity increases again 
until $\mathrm{x}=1$. For $0<\mathrm{x} \leq 0.9$ the thermal conductivity is decreased because the dominating lattice contribution is reduced due to the higher disorder and the inclusion of microstructures in the samples. The observed reduction of the thermal conductivity is very large compared to other reported substitutions in TiCoSb and TiNiSn [8, 19, 20].

\section{Insert Figure 4 here}

The electronic part of the thermal conductivity $\lambda_{\mathrm{e}}$ can be calculated by the WiedemannFranz law

$$
\lambda_{e}=\frac{L T}{\rho}
$$

with $L$ being the Lorenz number, $T$ the absolute temperature, and $\rho$ the electrical resistivity. For $\mathrm{x}>0.9$ the compounds become more metallic and the thermal conductivity is dominated by the electronic contribution. The electronic part of the thermal conductivity for $\mathrm{TiCo}_{1-\mathrm{x}} \mathrm{Ni}_{\mathrm{x}} \mathrm{Sn}_{\mathrm{x}} \mathrm{Sb}_{1-\mathrm{x}}$ is displayed in Table 3 .

It is well known that substitutions of $\mathrm{Sn}$ by $\mathrm{Sb}$ reduce the thermal conductivity [8]. The reported reductions were in the range of $0.5 \mathrm{Wm}^{-1} \mathrm{~K}^{-1}$. Since we observed a decrease in $\kappa$ of up to $8 \mathrm{Wm}^{-1} \mathrm{~K}^{-1}$ compared to TiCoSb the substitution of Sb by $\mathrm{Sn}$ is not the only reason for the reduction of the thermal conductivity. As an additional effect the phonon scattering at the grain boundaries has to be considered. Its contribution is dependent on the grain size as suggested by Bhattacharya [21]. The prolate Ti rich areas observed in the SEM micrographs are supposed to be the origins of the reduction of the thermal conductivity. The phase boundaries act as additional phonon scattering centers and reduce the thermal conductivity.

\section{Insert Table 3 here}




\section{Seebeck coefficient}

The Seebeck coefficient for $\mathrm{TiCo}_{1-\mathrm{x}} \mathrm{Ni}_{\mathrm{x}} \mathrm{Sn}_{\mathrm{x}} \mathrm{Sb}_{1-\mathrm{x}}$ is displayed in Figure 6. The highest measured value is approximately $-165 \mu \mathrm{VK}^{-1}$ at $810 \mathrm{~K}$ for $\mathrm{TiCo}_{0.8} \mathrm{Ni}_{0.2} \mathrm{Sn}_{0.2} \mathrm{Sb}_{0.8}$.

\section{Insert Figure 5 here}

For increasing $\mathrm{Ni}$ and $\mathrm{Sn}$ concentrations $\mathrm{x}$ the Seebeck coefficient is decreasing. The reduction is caused by the increase of the carrier concentration that was observed in the resistivity measurements. Closing of the gap increases the carrier concentration and therefore the absolute values of the Seebeck coefficients are reduced. It has to be taken into account that the simultaneous substitution of two atoms may have an opposing non-compensating effect on the Seebeck coefficient [22]. This can reduce the absolute value of the Seebeck coefficient as well. The calculated results for the Power factor are displayed in Figure 7. The highest values are achieved for $0.2<x<0.5$ at $900 \mathrm{~K}$. These values are in the same order of magnitude like state of the art materials [23], for which a figure of merit of 0.75 was reported. The observed broad maxima are located between $800 \mathrm{~K}$ and $900 \mathrm{~K}$. The great width of the maxima increases the temperature range where thermoelectric generators can be used efficiently.

\section{Insert Figure 6 here}

\section{Conclusion}

The series $\mathrm{TiCo}_{1-\mathrm{x}} \mathrm{Ni}_{\mathrm{x}} \mathrm{Sn}_{\mathrm{x}} \mathrm{Sb}_{1-\mathrm{x}}$ was synthesized by arcmelting and its transport properties were measured. The electrical resistivity was measured in the temperature range from 2 $\mathrm{K}$ to $900 \mathrm{~K}$. The resistivity behavior changed from semiconducting to metallic with an 
increase of the Ni and Sn content. The decrease in resistivity is explained by increased disorder and the closing of the gap at the Fermi energy.

The thermal conductivity was investigated in the temperature range from $2 \mathrm{~K}$ to $400 \mathrm{~K}$. The lowest value of $2 \mathrm{Wm}^{-1} \mathrm{~K}^{-1}$ at $400 \mathrm{~K}$ was achieved for the composition $\mathrm{TiCo}_{0.9} \mathrm{Ni}_{0.1} \mathrm{Sn}_{0.1} \mathrm{Sb}_{0.9}$. The low value is caused by mass fluctuation and point defect scattering as well as phonon scattering at the Ti rich microstructures. It has been shown that for Half Heusler compounds a thermal conductivity of $2 \mathrm{Wm}^{-1} \mathrm{~K}^{-1}$ or less is feasible with an introduction of micro segregations. The Seebeck coefficient was investigated in the temperature range from $2 \mathrm{~K}$ to $900 \mathrm{~K}$. The highest values were achieved for compositions with a high Co and Sb concentration. A Power factor of $9.2 \mu \mathrm{Wcm}^{-1} \mathrm{~K}^{-2}$ at $900 \mathrm{~K}$ was achieved which is in the same order of magnitude as modern state of the art materials. 


\section{References}

[1] Y. Xia, V. Ponnambalam, S. Bhattacharya, A. L. Pope, S. J. Poon, and T. M. Tritt. J. Phys.: Condens. Matter, 13:7789, 2001.

[2] D. Jung, H.-J. Koo, and M.-H. Whangbo. J. Mol. Struc. (THEOCHEM), 527:113, 2000.

[3] H. C. Kandpal, C. Felser, and R. Seshadri. J. Phys. D: Appl. Phys., 39:776, 2006.

[4] B. Balke, G. H. Fecher, A. Gloskovskii, J. Barth, K. Kroth, C. Felser, R. Robert, and A. Weidenkaff. Phys. Rev. B, 77:045209, 2008.

[5] K. Kroth, B. Balke, V. Ksenofontov, G. H. Fecher, H.-J. Lin, and C. Felser Appl. Phys. Lett., 89:202509, 2006.

[6] J. Tobola, S. Kaprzyk, R. V. Skolozdra, and M. A. Kouacou. J. Phys.: Condens. Matter, 10:1013, 1998.

[7] S. R. Culp, J. W. Simonson, S. J. Poon, V. Ponnambalam, J. Edwards, and T. M. Tritt. Appl. Phys. Lett., 93:022105, 2008.

[8] S. Sakurada and S. Shutoh. Appl. Phys. Lett., 86:2105, 2005.

[9] T. Sekimoto, K. Kurosaki, H. Muta, and S. Yamanaka. J. All. and Comp., 394:122, 2005.

[10] E. Müller, C. Stiewe, D. M. Rowe, and S. G. K. Williams. Thermoelectrics Handbook Macro To Nano. CRC, Boca, Raton, 2006.

[11] Quantum Design. Physical Property Measurement System Thermal Transport Option User's Manual. Quantum Design, USA, San Diego, 2002.

[12] S. Bhattacharya, A. L. Pope, R. T. Littleton IV, and Terry M. Tritt, V. Ponnambalam, Y. Xia, and S. J. Poon. Appl. Phys. Lett., 17:2476, 2000. 
[13] J. Barth, B. Balke, G. H. Fecher, H. Stryhanyuk, A. Gloskovskii, S. Naghavi and C. Felser. J. Phys. D: Appl. Phys., 42:185401, 2009.

[14] Y. Kawaharada, K. Kurosaki, H. Muta, M. Uno, S. Yamanaka. J. All. and Comp., 384:308, 2004.

[15] T. Katayama, S. W. Kim, Y. Kimura, and Y. Mishima. J. Electron. Mater. 32: $1160,2003$.

[16] P. J. Webster and K. R. A. Ziebeck. J. Phys. Chem. Solids, 34:1647, 1973.

[17] W. Jeitschko. Metall. Trans. A, 1:3159, 1970.

[18] L. Vegard. Zeitschr. f. Phys. A Hadr. and Nucl., 5:17, 1921.

[19] M. Zhou, L. Chen, C. Feng, D. Wang and J.-F. Li. J. Appl. Phys., 101:113714, 2007.

[20] M. Zhou, C. Feng, L. Chen and X. Huang. J. Alloy. Comp., 391: 194, 2005.

[21] S. Bhattacharya, M. J. Skove, M. Russell, T. M. Tritt, Y. Xia, V. Ponnambalam, S. J. Poon, and N. Thadhani. Phys. Rev. B, 77:184203, 2008.

[22] J. Yang, D. T. Morelli, G. P. Meisner, W. Chen, S. J. Dyck, and C. Uher. Phys. Rev. $B, 67: 165207,2003$.

[23] M. S. Dresselhaus, G. Chen, M. Y. Tang, R. Yang, H. Lee, d. Wang, Z. Ren, J.-P. Fleurial, and P. Gogna. Adv. Mater., 19:1043, 2007. 


\section{Figure Captions}

Fig. 1

XRD pattern of $\mathrm{TiCo}_{0.2} \mathrm{Ni}_{0.8} \mathrm{Sn}_{0.8} \mathrm{Sb}_{0.2}$. The arrows denote impurities. The inset shows the lattice parameter $a$ versus the Ni concentration $\mathrm{x}$.

Fig. 2

EDX measurement of $\mathrm{TiCo}_{0.1} \mathrm{Ni}_{0.9} \mathrm{Sn}_{0.9} \mathrm{Sb}_{0.1}$. Displayed are the micrographs taken in the Co K $\alpha$, Ni K $\alpha$, Ti K $\alpha$, Sn L $\alpha$, Sb L $\alpha$ lines and the integral image.

Fig. 3

Resistivity for $\mathrm{TiCo}_{1-\mathrm{x}} \mathrm{Ni}_{\mathrm{x}} \mathrm{Sn}_{\mathrm{x}} \mathrm{Sb}_{1-\mathrm{x}}$ for selected compositions.

Fig. 4

Thermal conductivity of $\mathrm{TiCo}_{1-\mathrm{x}} \mathrm{Ni}_{\mathrm{x}} \mathrm{Sn}_{\mathrm{x}} \mathrm{Sb}_{1-\mathrm{x}}$ for selected compositions.

Fig. 5

Seebeck coefficient of $\mathrm{TiCo}_{1-\mathrm{x}} \mathrm{Ni}_{\mathrm{x}} \mathrm{Sn}_{\mathrm{x}} \mathrm{Sb}_{1-\mathrm{x}}$ for selected compositions

Fig. 6

Power factor for $\mathrm{TiCo}_{1-\mathrm{x}} \mathrm{Ni}_{\mathrm{x}} \mathrm{Sn}_{\mathrm{x}} \mathrm{Sb}_{1-\mathrm{x}}$ for selected compositions 


\section{Table captions}

Table 1

Contribution of the atoms to the valence electron count.

Table 2

Atomic percentages of $\mathrm{TiCo}_{0.1} \mathrm{Ni}_{0.9} \mathrm{Sn}_{0.9} \mathrm{Sb}_{0.1}$ determined by EDX. Values are given in percent.

Table 3

Electronic part of the thermal conductivity $\lambda_{\mathrm{e}}$ for $\mathrm{TiCo}_{1-\mathrm{x}} \mathrm{Ni}_{\mathrm{x}} \mathrm{Sn}_{\mathrm{x}} \mathrm{Sb}_{1-\mathrm{x}}$. Values are given in $\mathrm{Wm}^{-1} \mathrm{~K}^{-1}$. 


\begin{tabular}{|c|c|c|c|c|}
\hline Compound & $\mathrm{X}$ & $\mathrm{Y}$ & $\mathrm{Z}$ & sum \\
\hline $\mathrm{TiCoSb}$ & 4 & 9 & 5 & 18 \\
\hline $\mathrm{TiCo}_{1-\mathrm{x}} \mathrm{Ni}_{\mathrm{x}} \mathrm{Sn}_{1-\mathrm{x}} \mathrm{Sb}_{\mathrm{x}}$ & 4 & 9.5 & 4.5 & 18 \\
\hline TiNiSn & 4 & 10 & 4 & 18 \\
\hline
\end{tabular}

\section{Table 1}

\begin{tabular}{|l|l|l|l|l|}
\hline & $\mathrm{Ti}$ & $\mathrm{Co}$ & $\mathrm{Ni}$ & $\mathrm{Sn}+\mathrm{Sb}$ \\
\hline $\mathrm{TiCo}_{0.1} \mathrm{Ni}_{0.9} \mathrm{Sn}_{0.9} \mathrm{Sb}_{0.1}$ & 38 & 4 & 29 & 29 \\
\hline
\end{tabular}

Table 2

\begin{tabular}{|l|l|l|l|l|}
\hline$X=0.2$ & $X=0.5$ & $X=0.8$ & $X=0.9$ & $X=0.95$ \\
\hline 0 & 0.6 & 0.6 & 0.8 & 5.3 \\
\hline
\end{tabular}

Table 3 


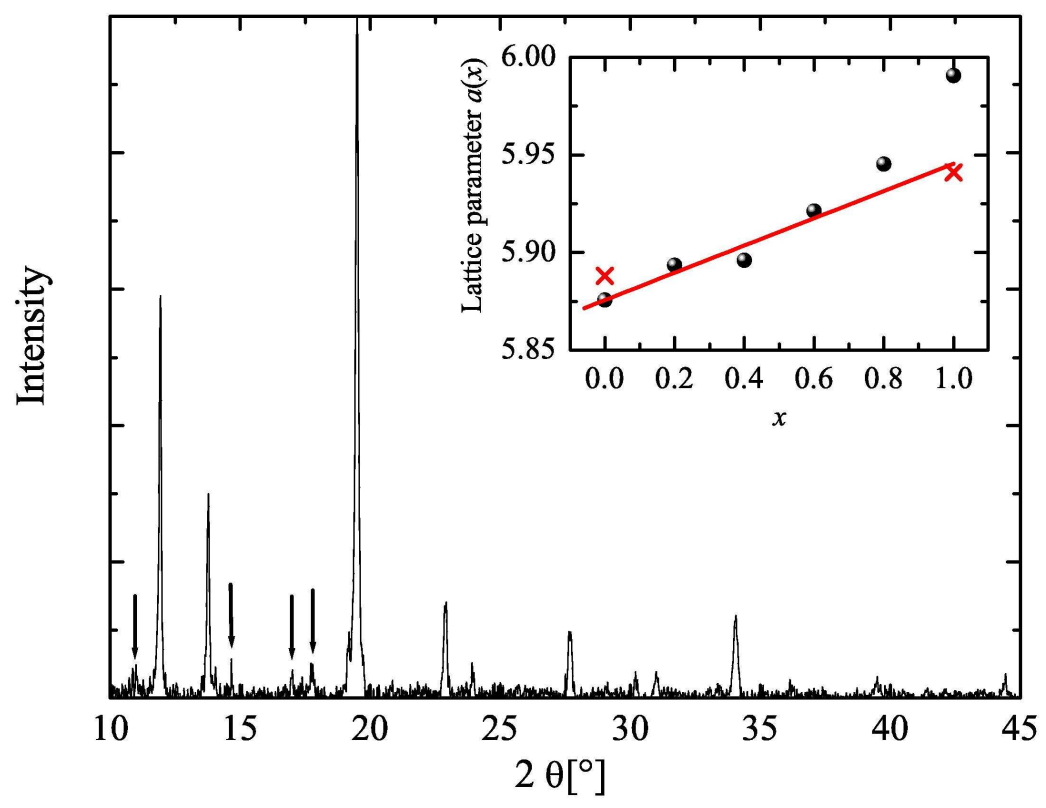

$115 \times 80 \mathrm{~mm}(600 \times 600 \mathrm{DPI})$ 


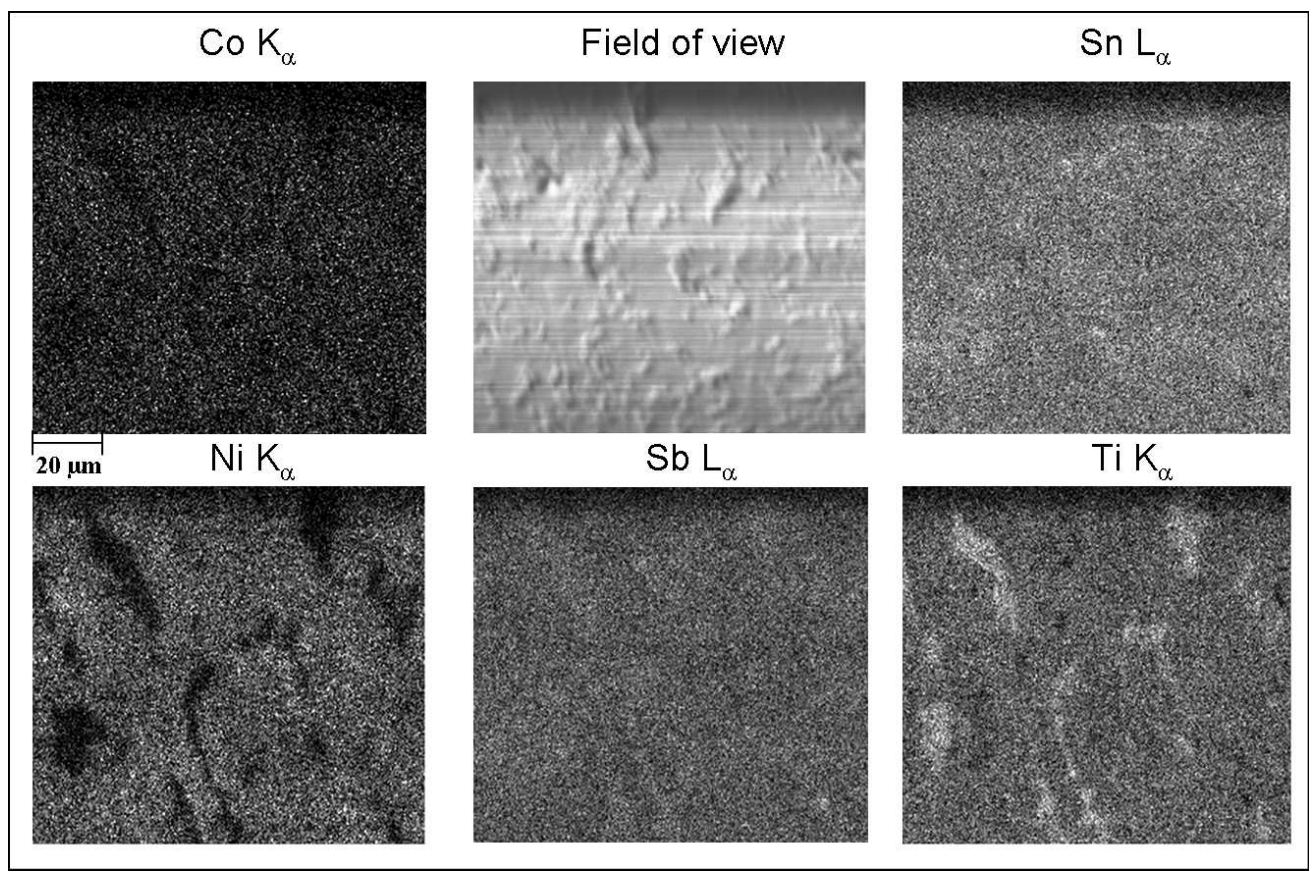

$224 \times 148 m m(150 \times 150$ DPI $)$ 


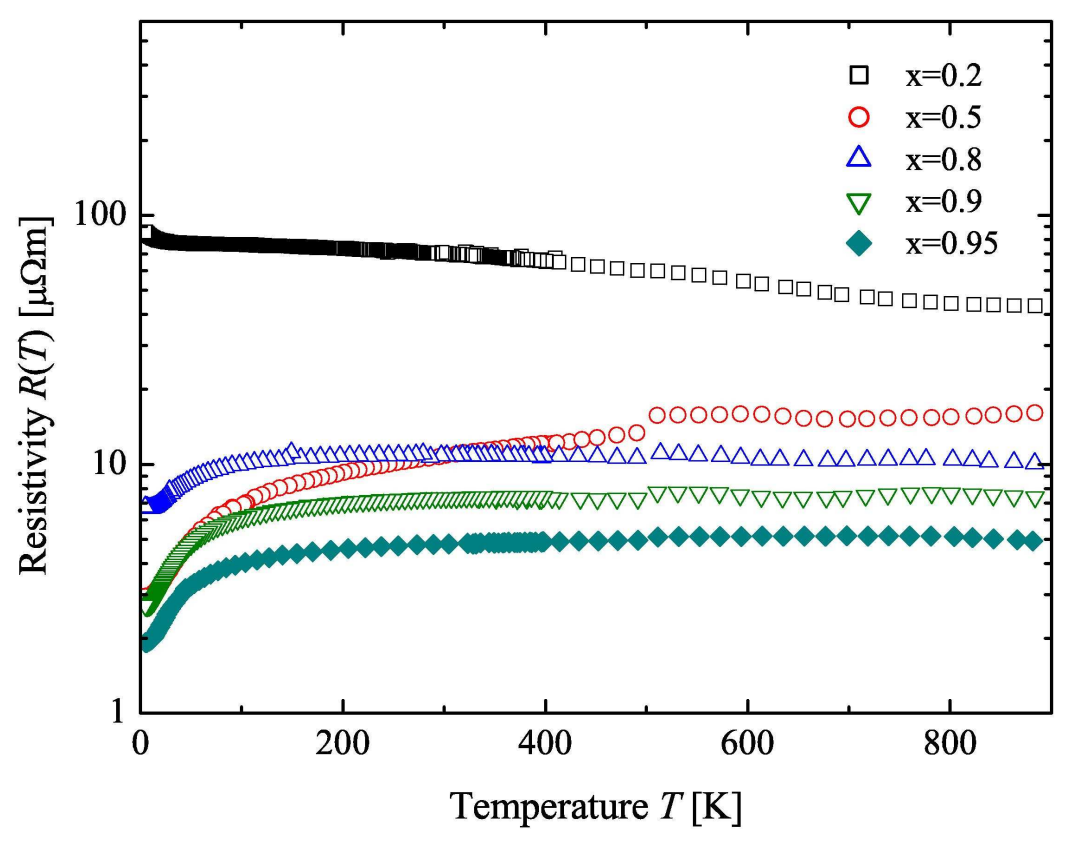

$118 \times 84 \mathrm{~mm}(600 \times 600 \mathrm{DPI})$ 


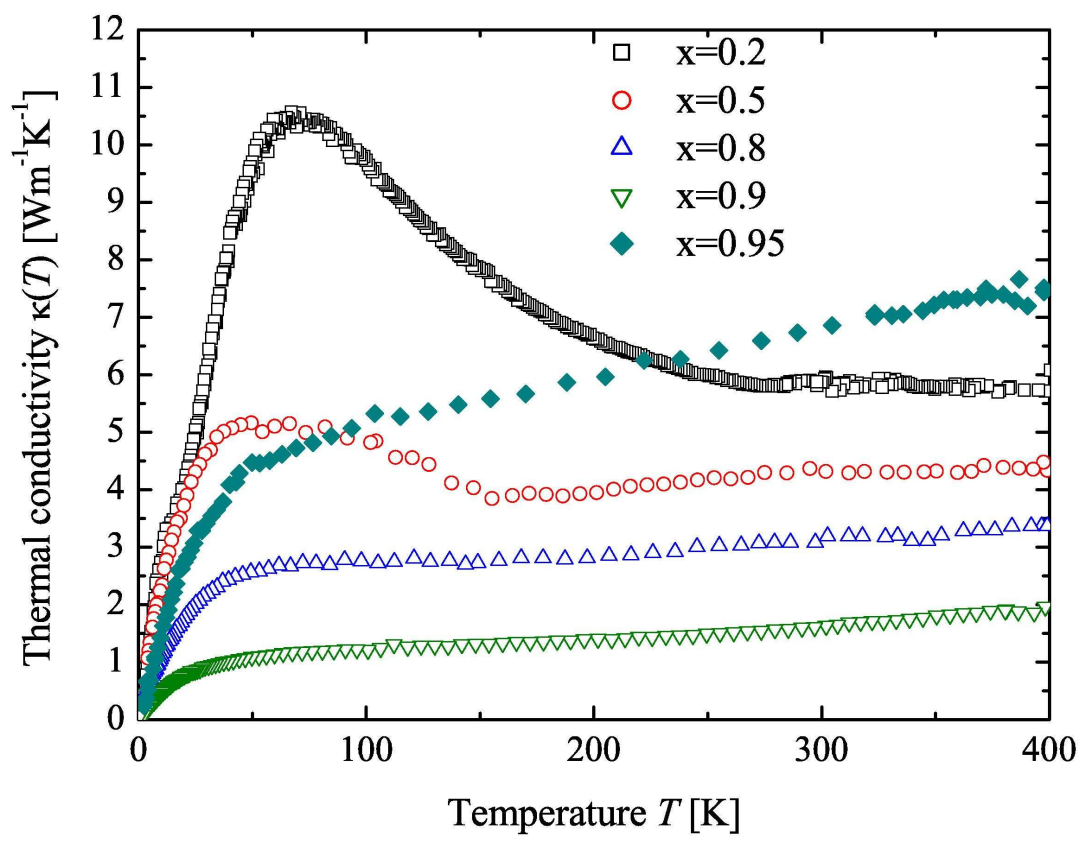

$118 \times 83 \mathrm{~mm}(600 \times 600 \mathrm{DPI})$ 


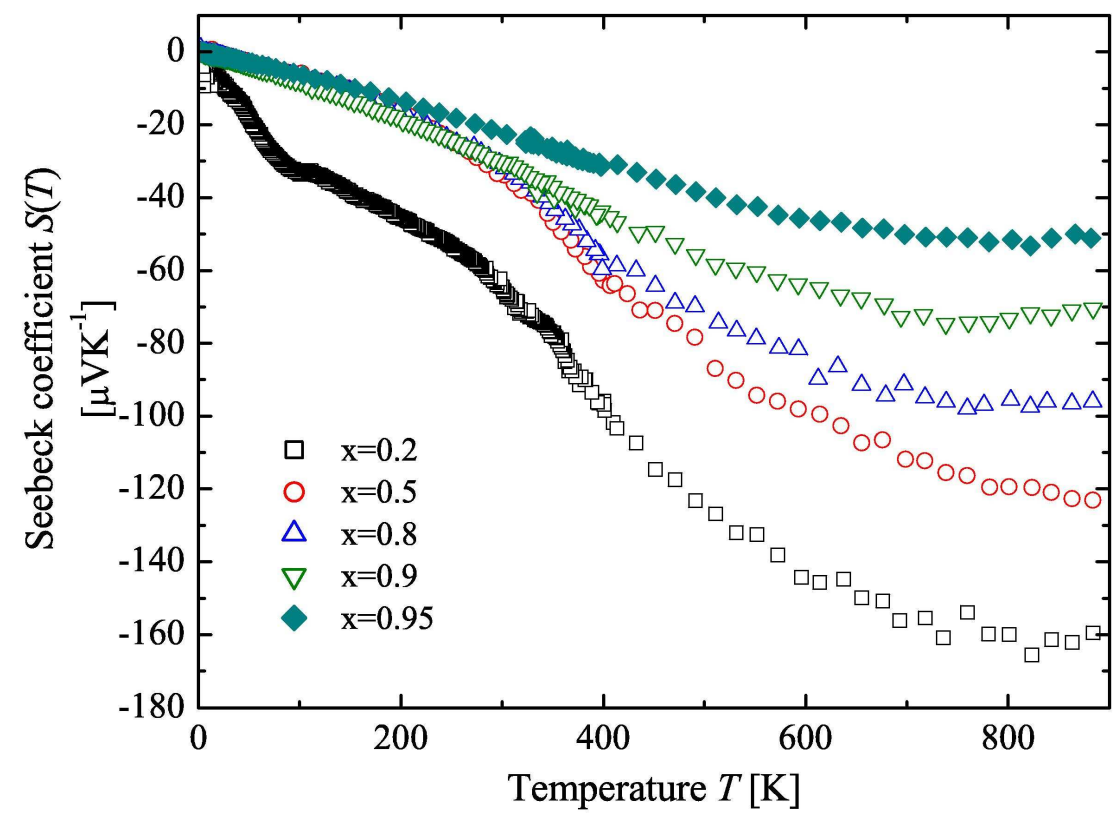

$118 \times 84 \mathrm{~mm}(600 \times 600$ DPI $)$ 


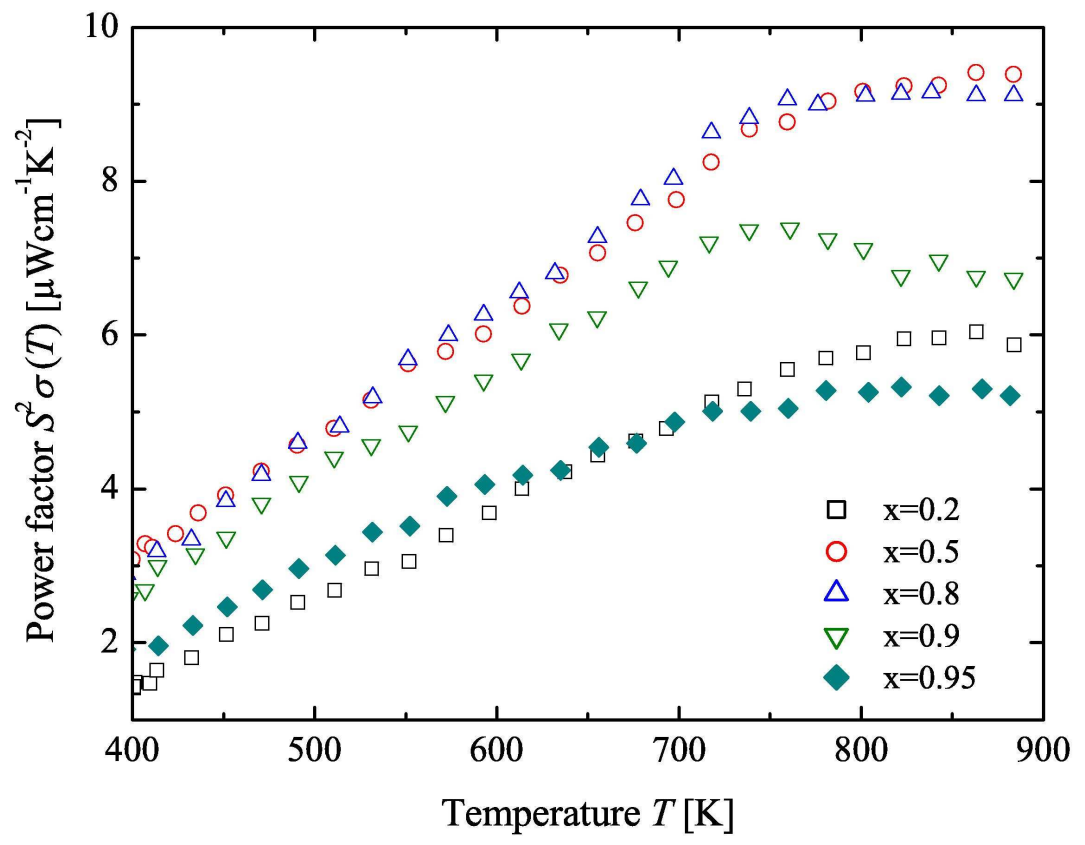

$118 \times 84 \mathrm{~mm}(600 \times 600 \mathrm{DPI})$ 